\title{
Riddles, Nonsense and Religious Language
}

In my recent book, The Great Riddle 1 (a revision of my 2014 Stanton Lectures), I sketch a way of understanding talk about God which I claim is faithful both to Thomas Aquinas and to Wittgenstein, in that it draws simultaneously upon, and so amounts to a synthesis of, two Wittgensteinian sources or models: his remarks about judgements of absolute value in the 'Lecture on Ethics', and his use of riddles as a lens through which to grasp the status of mathematical conjectures. In its epilogue, I reported an initial sense of consonance between these lectures and Rowan Williams' 2013 Gifford Lectures (published as The Edge of Words: God and the Habits of Language ${ }^{2}$ ), although I suggested that it might take either another book, or a revision of every chapter in my own book, to bring this out. Receiving the invitation to participate in this proceedings in the knowledge that Prof. Williams would also attend encouraged me to revisit that suspicion; and I now hope that the briefer span of an essay might at least further clarify that sense of consonance. To do so, however, I must first summarize my own argument.

\section{Absolute Value, Riddles and Great Riddles}

Its first source is Wittgenstein's distinction between a relative and an absolute mode of evaluative judgements. Take someone who claims to feel safe.

Ordinarily, this is a relative judgement: it is a claim to feel safe from something - a rabid dog, a threat to our reputation, a tsunami; what it means to be safe is thus determined by the specific threat, and we can always envisage what our current safety in fact depends upon, and how those factual conditions might be otherwise. But if I claim to feel absolutely safe, I invoke an idea of safety that is

\footnotetext{
${ }^{1}$ Oxford: Oxford University Press, 2015.

2 London: Bloomsbury, 2014; hereafter 'EW'.
} 
essentially unconditional - that is not a matter of being safe from anything in particular, hence is not keyed to any particular threat, and so is not vulnerable to any change of contingent circumstances or conditions, hence could not conceivably be overcome or subverted.

In effect, a familiar use of evaluative words has here been recast in such a way as to deprive us of our familiar way of making sense of it. And for Wittgenstein, this lack of coherence is their distinguishing mark: the verbal expressions of experiences of absolute value are essentially lacking in sense (and not because they are incoherently attempting to refer to phenomena in a transcendental realm). But as Cora Diamond has pointed out, accepting this resolute reading of absolute value judgements is entirely consistent with seeing their employment as intelligibly motivated, and so as possessed of significance - a significance they possess for their users (not despite but) by virtue of their nonsensicality. For if such a speaker finds satisfaction precisely in refusing any available assignments of meaning to her words, then understanding her means understanding why she might find such assignments essentially unsatisfying. In both the Tractatus and the later lecture, the specific kind of meaningassignment to ethical utterances that is being resisted is that characteristic of fact-stating, empirical discourse in general, and of empirical psychological discourse in particular. Hence, the unconditional nature of the refusal indicates a sense of absolute discontinuity between this conception of the ethical and the empirical world. Evaluating threats can be understood perfectly well in naturalistic terms; so can the use of language to alter people's feelings and attitudes, or to express adherence to prescriptive principles, or to guide action. So by refusing to accept any such assignments of sense to his utterances about absolute value, Wittgenstein draws a sharp contrast between two kinds of evil (and hence two kinds of good): in Diamond's words, 'evil [that] is... inconsequential..., something close to home... something [not] very bad to 
which one might become accustomed, and [evil as] something terrible, black, and wholly alien that you cannot even get near' (EIM $\left.{ }^{3}, 85-6\right)$.

Recall Grimm's fairy tale about the fisherman who rescues a magic flounder, who then offers to grant his rescuer whatever he wishes; the fisherman's wife begins by asking for a better home and ends by expressing dissatisfaction at the sun's and the moon's rising independently of her will - at which point a cosmically destructive storm arises from the flounder's ocean and returns her to the pig-sty in which they had originally been living. Being dissatisfied at living in a pig-sty is not only not evil, it may even seem essential to anyone's sense of self-respect; so the wife's transition to her climactic dissatisfaction may appear to be seamlessly comprehensible. But to see her final demand as the endpoint of some intelligible process of moral deterioration, one must overlook the fact that wanting the world to conform to her will amounts to wanting it not to be a world at all; it requires the unintelligible idea of her occupying God's perspective on the world. To see in this nothing more than an unwise but understandable over-extension of an essentially healthy self-regard would be to obliterate the distinction between genuine human needs and worldextinguishing hubris.

The early Wittgenstein's removal of thought and talk about the good and evil will from the empirical realm is another way of marking that contrast - one of a number of possible techniques of language through which it might be indicated and maintained. The dissatisfaction of the fisherman's wife is akin to that of the unhappy man of Wittgenstein's Tractatus, who is dissatisfied at the world regardless of how things go within it, hence not so much dissatisfied with how that world is as with the bare fact of its existence, with its sheer independent reality - its refusal to meet the conditions he lays down, to submit to his control. The discontinuity is manifest in the unintelligibility of the dissatisfaction (for

\footnotetext{
3 'Ethics, Imagination and the Method of the Tractatus', in Crary and Shieh (eds), Reading Cavell (London: Routledge, 2006).
} 
what would it be like if the world did answer to the conditions either lays down?); and yet, both techniques for marking it simultaneously acknowledge an underlying continuity.

The cosmic dissatisfaction of the fisherman's wife is intuitable even in her initial desire to have a cosy little house rather than a pig-sty: the tale explicitly marks this by noting that the sea is already faintly discoloured and mildly turbulent when the fisherman brings his wife's first wish to the flounder's attention, quite as if the world-annihilating storm she eventually unleashes is already gathering its energies. So the wife's catastrophic hubris is at once something absolutely out of the ordinary, and yet always already lurking beneath the surface of the most innocuous expressions of human will. Her terrible evil is essentially irreducible to everyday moral and psychological understanding, and yet somehow haunts them: that is why, however much violence we must do to their familiar modes of use, it is precisely these words (the ones we employ to talk intelligibly about intra-worldly objects of desire and dissatisfaction) to which the violence must be done if what we intend by our utterance is to be satisfied. Nothing other than the failure of sense resulting from that violence could convey the simultaneous continuity and discontinuity we mean to capture; it is the unintelligibility of these forms of words that alone can articulate the resistance of such evil to our comprehension.

The words that comprise expressions of absolute value thus remain devoid of sense; but we can make sense of their being so employed, and so of those employing them, if we can see their lack of sense in this evaluative context as a denial or deconstruction of the sense they make in other evaluative contexts - as a stripping away of those specific patterns of sense-making. We relate to them not as simply lacking sense but as lacking that particular sense, as deprived of or refusing that familiar meaning (so that each bare mark is marked by the present absence of its symbolic individuality, by that which its user's refusal necessarily invokes). This is not a matter of grasping the peculiar internal logic 
of an expression of absolute value (since it has none), but of grasping what Nietzsche might call its genealogy; we appreciate the peculiar significance of uttering such nonsense by seeing it as an intelligible outworking of the broader forms of human life within which the words uttered have uses whose internal logic and overall significance can be more straightforwardly grasped.

My second source is Wittgenstein's comparison of a mathematical conjecture that lacks a proof to a riddle for which we have not found a solution ${ }^{4}$. Suppose I ask: 'What has four legs in the morning, two at noon, and three in the evening?' To solve this riddle, you need to know more than what that form of words describes; you need to know how it describes it - to see how a human being might be seen as fitting that description, how those words might be seen as a description of human existence. If so, then until we have the solution to the riddle, together with an understanding of how it counts as a solution to it, to that extent we lack an understanding of the riddle-phrase that the question employs, and so lack an understanding of the question. It may seem clear in advance that any solution will have to meet certain conditions - for example, that if something has four legs, it must have more than two legs; but that would (falsely) imply that the solution to our riddle cannot be a human being. In other words, we no more understand the further conditions we might impose on a solution to our riddle than we understand the riddle itself: part of grasping its solution as a solution will be grasping how it can be said to meet these ancillary conditions, and so those conditions can't be said to control what will count as a solution.

However, our imaginative engagement with the riddle is controlled by something - by existing patterns of use in our language, on the basis of which the riddle-phrase has been constructed. In this case, there are existing patterns of

\footnotetext{
${ }^{4}$ Cf Wittgenstein, Lectures on the Foundations of Mathematics, Cambridge 1939 (Chicago: University of Chicago Press, 1989); ed. C. Diamond - p 84.
} 
employing number words, of describing animal anatomy and its supplements, and of measuring time; and familiar ways of extending those patterns - for example, comparing different ways of measuring time (measuring the course of a life in terms of the progress of a day). Finding a solution to the Sphinx's riddle is a matter of finding an appropriate way to project all those patterns onto it; we are not seeking something of which we have been given a determinate description, but something that it will strike us as right to call by the riddlephrase. The familiarity of the phrase's construction, and of its grammatical connections with other phrases, orients our seeking, and gives the phrase whatever meaning we wish to say that it has at this pre-solution stage; but we cannot simply read off what we will be prepared to count as its solution, or indeed whether there is one.

Wittgenstein sees an analogy here with our relation to a mathematical conjecture that lacks a proof. By fixing its place in the system of mathematical propositions, a proof gives the conjecture a determinate meaning it hitherto lacked, although the task of seeking a proof of it is given such orientation as it has, and so the conjecture has whatever meaning we may wish to say that it has for us prior to the construction of that proof, by virtue of our familiarity with other mathematical concepts and procedures on analogy with which the conjecture has been constructed. And Diamond suggests ${ }^{5}$ that Anselm's ontological argument can be illuminatingly regarded as a working out of just such promissory connections in the domain of theology, with respect to the riddle-phrase 'that than which nothing greater can be conceived' (hereafter TTWNGCBC).

That phrase is constructed on the basis of a familiar model (great, greater, greatest, greatest conceivable); and Anselm draws upon existing linguistic connections between lacking something, being limited, being dependent, coming into existence and having a beginning in order to establish that if we

\footnotetext{
${ }^{5}$ In 'Riddles and Anselm's Riddle', collected in The Realistic Spirit (Cambridge: MIT Press, 1991).
} 
were to call anything TTWNGCBC, then it would be something that had no beginning. We understand 'something that has no beginning' as much and as little as we understand 'TTWNGCBC'; the link we establish between them is the outer shell of a necessary connection in a language we do not yet know how to speak. We are entertaining familiar words combined in a familiar pattern, holding open the possibility of a new language-game in which that word-shape has a place and in which we might find ourselves at home; but if that possibility were realized, it would be the discovery of a logical space, not a discovery within one.

Anselm's emphasis on the difference between existence in the understanding and existence in reality then appears as a (potentially misleading) way of distinguishing between ideas that we can, and those that we cannot, conceive of being the result of human inventive capacities. He wants to emphasize that our conception of what is possible might itself be shown up by reality - that reality might show us not only that something is the case that we imagined was not, but that something beyond what we had ever taken to be possible, something beyond anything we could imagine as possible, was actual. If there were anything answering to that condition, it must also be such that we could not imagine it never having existed. For if we could, then we could separate the idea of it from its actuality, could make sense of the possibility of its being a mere possibility to which nothing actual happened to correspond; but then we could conceive of something greater than it - something whose actuality is a condition for the possibility of conceiving it, something without which it is inconceivable that we could possess a language of any kind for it. Hence, anything we were willing to count as TTWNGCBC would have to be something whose nonexistence could not be conceived, something that is conceivable only on condition of its actuality.

In the case of ordinary riddles, and mathematical proofs, Diamond argues that it is only when we discover a solution to the riddle, and how it counts as a 
solution, that we fully understand the question the riddle poses; before this, the relevant phrases have only promissory meaning. But in the case of TTWNGCBC, Anselm establishes that every statement we can make about it can only have a promissory meaning; the full transparency of that language to us is ruled out, because if we could fully grasp its meaning now, then we could conceive of something greater than whatever those words describe (namely, something whose nature exceeds the grasp of any concepts of which we can even conceive). And of course that form of words ('something whose nature exceeds the grasp of any concept of which we can even conceive') is no more fully transparent to us than any other form of words to which it is 'grammatically' linked, via the outer shell of a 'necessary connection'. All are 'allusions' to a 'language' we cannot even conceive of speaking before actually finding ourselves in a position to speak it - a language given to us by the being to whom it applies, and whose revelation of himself will effect the radical conversion of all our existing concepts of him.

The phrase TTWNGCBC thus stands in need of a determination of meaning which must come not from us but from whatever it turns out to apply to. Since ordinary riddle phrases can be given meaning by us, insofar as we can find a way of meaning them, Diamond talks of riddle-phrases such as TTWNGCBC as embodying a great riddle (alluding thereby to Wittgenstein's Tractarian invocation of the 'question' of the meaning of life, which he tells us will remain even were we to arrive at answers to all our articulable, grammatically coherent questions, and to which he tells us there is no conceivable solution, only a dissolution of the question).

My synthesis of these two Wittgensteinian sources is effected by applying them to Aquinas along lines inspired by Grammatical Thomists such as David Burrell and Herbert McCabe. I argue that the whole project of the Summa can be seen as a creative response to the enigmatic authority of one particular riddling 
phrase from scripture - one amongst many scriptural and doctrinal shapes of truth that Aquinas treats as divinely authorized or inspired acts of speech, hence as aspects of God's revelation of Himself to us, but which therefore necessarily present themselves to us as inherently mysterious or enigmatic. This anchoring phrase is introduced very early in Aquinas' treatment of his first question, 'the nature and scope of sacred doctrine': having argued that we required instruction from divine revelation not only to supplement the disclosures of human reason, but also to place reason's deliverances in the right light, in Article 3 he declares that 'Sacred doctrine ... is chiefly concerned with God, and it turns to creatures considered as being in relation to him, their origin and end.' $\left(1 \mathrm{a} .1,3, \mathrm{ad}^{6}{ }^{6}\right)$. The Scriptural basis for such a characterization of God lies in passages such as this, from the Book of Revelation (22: 13): 'I am Alpha and Omega, the beginning and the end, the first and the last'.

The opening question which orients the Summa (with its tripartite structure embodying a vision of all reality as flowing from and eventually returning to its divine source) thus takes its bearings from that Biblical phrase - treating it as its own alpha and omega; and the rest of the Summa attempts to make such sense of that riddle phrase as is possible, by working out the promissory connections between this phrase and as many as possible of the other riddling shapes of truth bequeathed to us by scripture and tradition, given the concepts and procedures more generally available to us. He thereby constructs the 'grammar' of a 'language' whose adequacy to the divine reality is guaranteed by the authority of its source, but which we are not and cannot be in a position simply to speak. We understand that God is the solution to all the riddles out of which this 'language' was been woven, but not how He is.

The Five Ways are Aquinas' initial attempt to impose conditions on the kind of solution to that riddle that we might accept. If we are willing to call anything

\footnotetext{
${ }^{6}$ All quotations from the Summa are taken from the translation in Davies, B., and Leftow, B. (eds), Summa Theologiae: Questions On God (Cambridge: Cambridge University Press, 2006).
} 
'the beginning and end of all things', would we be willing to call it a thing - an object, a substance, an individual particular? Well: according to Thomas' best understanding of thinghood, any thing is alterable, capable of causing alteration in other things only insofar as it is capable of being made subject to their causal efficacy, capable of going out of existence, imperfect and capable of being subject to the goal-directedness of others. In one sense, therefore, the realm of things gives content to the very idea of 'beginnings' and 'ends' out of which the riddle phrase is constructed: without a grasp of alteration and its causes, contingent as opposed to necessary existence, and the way in which values can function as standards and goals, and so bring things and activities into being for the sake of fulfilling an end, we would have no initial grasp on the riddle phrase. But precisely because that initial grasp is conditioned by its applicability to things amidst other things (that is, as part of a world in which what alters or destroys a thing, what shows it to be lacking or puts it to goal-directed use, is some other thing), appreciating that fact has two consequences.

First, it naturally generates the impulse to put together the ideas of beginning and ending in a less conditioned or relative way - to construct the concept of something that is (not the beginning or ending - whether causal or teleological of some particular thing or things but) the beginning and end of all things. And second, it entails that anything answering to that description could not itself be a thing: for then some other thing could in principle constitute its beginning or end. Accordingly, whilst we couldn't have constructed the idea of 'the beginning and end of all things' except out of our conception of what it is to be a thing amongst other things, that point of origin at once implants a natural projective trajectory for the relevant expressions and excludes the possibility that whatever answers to the resulting linguistic construction (what fulfils the intellectual desire articulated thereby) could be any such thing. If 'the beginning and end of all things' cannot be a thing, then it cannot have the ontological profile of a thing. And the Five Ways implicitly spell out what 
Aquinas takes to be the crucial aspects or dimensions of that ontology: the distinction between matter and form (integral to the First and Second Ways), the distinction between essence and existence (implicit in the third way), and the distinction between a thing's present actualization of the norms and ends internal to its nature and the fullest possible such realization (invoked in the fourth and fifth ways). These elaborate our core conception of what it is for a thing to have a nature, a particular manner or mode of being; and they display that and how any given thing is necessarily open to other things (necessarily capable of variously affecting and being affected by them) in the system of nature. If such divisions or diremptions - such structural multiplicities - are internal to thinghood, then 'the beginning and end of all things' must lack them: where things suffer a kind of non-self-identity, one might say, 'the beginning and end of all things' must be genuinely self-identical - wholly one, absolutely simple.

Here, the process of condition-construction for this Biblical riddle phrase makes contact with another such phrase - one that Aquinas cites immediately before developing his Five Ways: 'Exodus represents God as saying 'I am who am' (Exodus 3:14). This great tautology immediately denies that, with respect to the beginning and end of all things, one could make a distinction between essence and existence; but since such a denial entails denying the applicability of the distinctions between form and matter and telos and actuality, it confirms what our imaginative conjecture based on the riddle phrase from Revelation independently displays - divine simplicity. And this is the insight from which Aquinas begins in his third Question, which orients the rest of his treatment of our ability to know and name God in the Summa.

David Burrell formulates Aquinas' way of formulating the Exodus tautology as follows: 'to be God is to be to-be'; or, slightly more telegraphically: 'to be God is to be'. Wittgensteinians such as Anthony Kenny and Bede Rundle find it hard to imagine anything more radically absurd or lacking in sense; but sheer 
nonsensicality is precisely the point. The Five Ways taken individually or collectively, or the Biblical phrases that orient Aquinas's treatment from its outset, are exemplary instances of great riddles; and what distinguishes great riddles from mere or simple riddles is that an intelligible answer to them is not just a leap of the imagination away (as it is for the princess who, told to come to the ball neither clothed nor unclothed, attends wearing a fishing net). On the contrary, their significance for us as questions depends on our excluding a priori the possibility that we might construct a satisfactory answer to them out of our own resources.

Take the Second Way. If the radical causal question it articulates (not 'Why this as opposed to not-this?' but rather 'Why this as opposed to there being nothing at all?) is itself a great riddle, it has such sense as we are inclined to attribute to it by virtue of our familiarity with the concepts and procedures of causal explanation on analogy with which it has been constructed; and one condition we impose on the kind of answer to the question that we are willing to accept is that the creator of everything cannot possess or instantiate a kind of causal power (since our everyday grasp of causal explanation tells us that causation is a process by which one thing is made to be or to be otherwise by the operation of another thing upon it or upon that from which it is made). But it is not just that divine Creation ex nihilo is necessarily not any kind of human creative activity; it is equally essential that the very meaning of the word 'Creation' in this context is not the result of human linguistic creativity. For if that phrase forms part of a great riddle, its meaning can only be given to us, and by the very Being to whom it will at last successfully refer (when, and only when, we meet Him face to face); and one way of expressing that conviction is to refuse to accept any proffered specification of a grammar for these words, precisely on the grounds that doing so would confer intelligibility upon them. Faith herewith finds a use for nonsense that is significantly different from the (primarily 
ethical) one we explored in the Tractatus and the Grimm's fairy tales, and yet not unrelated to it.

\section{Silence Speaks: Three Glances at the 2013 Gifford Lectures}

At first glance, Rowan Williams' Gifford Lectures seemed uncannily close to my own. Looking at the first chapter alone, the issues and reference points touched on include: the extraordinariness of ordinary speech, the limitations of a descriptive model for religious discourse, Aquinas, pushing everyday modes of causal explanation to the point at which we are compelled to change linguistic gear, Wittgenstein, analogical uses of words, Cavell, difficulties of reality, conversational exchanges, riddles, revelation, Kenny, objects understood as informed matter dependent on pure activity, excessive or projective speech, the intellect being ordered to what it cannot know, and so apparently endlessly on. A second glance suggested, however, that these shared elements were in fact being organized or ordered towards an end that might be the exact opposite of the one to which my book attempted to direct them. To be sure, Williams begins by rejecting the suggestion that we should

portray God and God's dealings with the world as simply another department of description: here is an agent with these properties and habits, to be added to the list of other agents with properties and habits [, as if] God 'comes in' as an extra item in our routine description of what is the case. $(\mathrm{EW}, 4)$

For him, speaking of God is characteristically or primitively something quite other than this; indeed, it 'comes in' by demanding a linguistic response that disrupts such descriptive routines. But he immediately emphasizes two points. First, there are many

moments in our familiar perception and discourse where familiar description fails... because something is apparently demanded of us - in order to make an adequate linguistic response to our situation - which is 
not just another attempt to describe agencies negotiating with one another or combining to effect a specific outcome. It is not only that answers fail to come - we have to think again about the questions. Second, we need to explain why a response to this 'something demanded of us' is not properly understood as an arbitrary move, drawing us away from precision, labour, or indeed truthfulness... It is more like putting the question 'What sort of truth can be told only by abandoning most of our norms of routine description?' (EW, 5-6)

Williams devotes separate chapters to various exemplary aspects of our ordinary practices as speakers in which those norms are abandoned or otherwise put in question in order to respond truthfully to reality's demands. Beginning with a reminder of our freedom as language users (the fact that our speech is not reducible to patterns of stimulus and response, and so not comprehensible as behaviour determined by the causal impact of given elements or states of affairs), he goes on to stress the temporality of speech (its insights being achievements of successive exchange that are always open to fresh events of speaking and hearing), its embodiedness (its rootedness in equally provisional and open-ended physical transactions), its excessiveness (its deployment of creative forms of utterance that enlarge language by making us strangers to ourselves and our world) and its capacity for silence (for suspending itself as a strategy for furthering the goals of truthful response rather than abandoning them).

Williams calls these phenomena modes of representation rather than description: where descriptions are a mapping exercise designed to produce a traceable structural parallel between what we say and what we perceive, usually with a view to manipulating it, representations 'seek to embody, translate, make present or re-form what is perceived'. So representations retain an orientation to truth, without purely reproducing or imitating discrete elements of the world or our experience of it; they answer to something largely irrelevant to prediction 
and control, something more like a sheer desire to understand and to enlarge the repertoire of communication. In his first chapter he cites a range of contexts (in Western and Eastern religion, in science, in art) in which this ideal of description-disrupting responsiveness finds analogical expression; and he suggests that its pervasive enactment in our life as speakers suggests a metaphysical vision of reality as 'a continuum of analogical relations in which we can speak of one thing in terms of another, of [relations of] participation existing between not only object and object in the world, but between object and representing subject.' (EW, 20). This is because to represent anything presupposes that something of what is perceived can 'come to be' in another medium - that it has a characteristic form of action or energy ('energeia') that can be activated within another phenomenal shape, and so can in some ways be more clearly apprehended when transplanted from its original embodiment to another context.

To illustrate such 'playing away from home', Williams invokes the lion-men statuettes produced in the Ice Age era of home sapiens' evolution: figures with lions' heads and human bodies partly shaped in leonine form. They are depictions of one thing seen as another thing, thereby at once blurring the boundaries between lions and humans and sharpening our grasp of both; and they indicate the active presence of a mind capable of conforming itself to both things in ways that do not simply reproduce them but create a new hybrid conception - a mode of responsiveness to reality that is the opposite of the merely playful, or more precisely that reveals such creative, excessive play to be a way of laboriously and rigorously achieving deeper understanding of reality, and of contributing thereby to the materially and temporally embodied communicative exchanges that make up free linguistic inter-action, those characteristic forms of activity of the human being.

To sum up, then: although Williams regards talk of God as coming into everyday discourse in such a way as to unsettle its descriptive routines, he 
emphasizes that it is not only talk about God that has this kind of disruptive effect (and so, that religious discourse is not uniquely out of step with an otherwise resolutely descriptive linguistic drive), and he spends most of his time examining the ways in which so-called ordinary speech is in fact shot through with a variety of such non-religious representative registers, consciously excessive or eccentric modes of responsiveness to reality. Together, they imply a relation between knower and object of knowledge in which the latter is active beyond the grasp of the knower, but in a way which provokes us to rethink how we might more truthfully talk about it. If, however, such an indeterminate yet intelligible hinterland belongs to every percept, then our experience suggests that reality consistently gives itself to be known. The activity we meet in objects is congruent with our own, and so represents a feature of activity as such, of being as such, moving into our subjectivity as a presence that enlarges our capacity and serves our welfare. It suggests a prior reality of address, to which we are always subsequent and which we are always seeking to receive appropriately.

The indeterminate diversity of representational possibility points us towards an abundance that is always bound up in understanding, always rooted in the intelligible, and also active in bestowing its activity on and in what it is not. The scheme that is called up as these considerations are spelled out is, ultimately, that of an unlimited intelligence and love... an act of intelligent and beneficent 'bestowal'. (EW, 32)

If this summary is accurate, Williams' argumentative strategy and my own appear antithetical: for presenting God-talk as a mode of representation relates it to truth, knowledge and sense-making in a way my approach resists. Take his treatment of riddles, and of Aquinas' Second Way. Williams explicitly cites riddles in his first chapter, when arguing that both descriptive and representative modes of speech presuppose schemata of understanding. A schema is 'a complex of use and association or resonance and recognition patterns or habits' 
(EW, 23); and for Williams there is an irreducible plurality of them. They are not quickly exhausted, and we cannot say in advance just how diverse their range might be; we can only try them and see.

An overwhelming number of cultures deliberately push this as a social and intellectual game: how obscure can you get before recognition disappears? Hence the riddles so popular in pre-modern cultures, in which elaborate metaphorical strategies are consciously developed to make recognition difficult, and so to extend still further the range of what can become part of a communicative exchange... [W]e couldn't say in advance how many possible riddling 'kennings' there might be for familiar objects.. [T] here is an indeterminate - or, perhaps better, underdetermined - element in representation so understood. (EW, 26-7) Riddles here function as one way in which the creative human imagination might deepen our understanding of reality and of one another. They exemplify exactly what Wittgenstein's invocation of them in attempting to understanding mathematical conjecture exploits: their ability to prompt the discovery of a new logical space rather than a new discovery within an established logical space. In this respect, riddles fit neatly within Williams' investigation of excessive speech. He begins that chapter with a quotation from Margaret Masterman: 'Paradox is the most extreme kind of metaphor, just as metaphor is the most extreme kind of simile'; since Williams has already implied that riddles are an extreme kind of metaphor, they would presumably be located towards the paradox end of Masterman's spectrum, and thereby exemplify the ways in which paradox can be a vehicle of enhanced insight.

With all of this, I would heartily agree. But Williams' account does not mark a distinction that is pivotal to my own, and so to my understanding of talk about God - the distinction between riddles and great riddles. His interest in riddles seems exclusively directed to that use of them in which it is in principle possible to construct an answer to them, and thereby maintain the possibility of 
intelligible, truthful discourse about reality employing the relevant riddle phrases. Whereas I argue that it is internal to the riddle phrases that are central to talk about God that the possibility of assigning a sense to them is excluded $a$ priori, for the purposes they serve require that we maintain a relation to them as having been violently dispossessed of any such sense.

A parallel sense of divergent goals likewise appears to surface in Williams' opening discussion of Aquinas and his Ways, particularly the Second.

[Aquinas] is... inviting us to develop the discourse of causality to the point where we sense the need to change gear: everything we encounter is involved in relations of dependence; if dependence is built in to how we make sense of anything at all, are we bound to find ourselves looking for a language to express some sort of global dependence?

$[I] f$ it is part of the definition of every particular intelligible phenomenon we encounter that it is contingent, ie the result of a process of some sort, we can reasonably say that it is part of the definition of finite and intelligible being that it is invariably involved in process of causation and thus marked by dependence. All energy we encounter is involved in energy exchanges; but are we not then pushed to ask about the character of energy as such (pure act...), energy that is simply what or as it is, not as the result of a process of exchange? If we move in that direction... we do not seek for another object to explore. It cannot be an instance of anything... Something is required which is expressible only in connection with the language of dependence, yet cannot be formulated within the normal frame of reference that we use to deal with causal relations. If dependence is built into the structure of all possible experience and understanding, we are saying that to be anything intelligible at all is to be caused; we could leave it at that, but this would... ignore the question about whether and how we 'frame' this comprehensive statement. And the frame proposed is... that finite being as such and in sum is marked by 
dependence: to exist as a discrete subject of predication is to depend. So that which is depended on is evoked or gestured to; but... we can't formulate a sensible question as to what sort of thing it is that doesn't depend because... we have now moved away from asking about sorts of things, and the questions we started with no longer move us forwards. (EW, 9-10)

This is a long passage, but I quote it in full because it seems to me vitally ambiguous (or capable of being taken in the spirit of the Cantabrigian Denys Turner rather than the Oxonian Herbert McCabe, as my book might have it). Take the example of energy: on the one hand, Williams acknowledges that all energy we encounter is involved in energy exchanges, so presumably by definition there is no such thing as energy taken in isolation from such exchanges; but then he appears to suggest that we can ask intelligibly about the character of energy as such. We don't have to do so: we could simply stop by noting the internal or grammatical relation between energy and exchange, as he says we can simply note the grammatical relation between finite beings and dependence. But he also says that stopping in this way ignores the question about whether and how we 'frame' such a comprehensive statement. What exactly this question may be, what it amounts to, is left frustratingly unclear; but Williams' candidate answer ('to exist as a discrete subject of predication is to depend') is not treated as a mere restatement of the grammatical relation. It is rather said to evoke or gesture to that which is depended on (by any or all finite beings), even though we can't formulate a sensible question as to what is thereby evoked or gestured to.

But doesn't our inability to formulate such a question show that we can't intelligibly think of Williams' proposal as evoking or gesturing to anything either? Williams seems to think that the relevant question isn't sensible because it presupposes that we are seeking a sort of thing, when we have left that discursive frame behind; but since not all speech is descriptive in that way, he 
thinks that leaves open the possibility of moving forward as speakers in another way, in a different linguistic gear - that of evoking or gesturing. In short, such religious evocations of that from which everything depends, of energy as such, of being are genuinely truth-seeking modes of representing reality, hence intelligible ways of responding linguistically to what is given to us as comprehending beings.

This sense that Williams wants to see talk about God as basically continuous with the other disruptive but nevertheless intelligible representative modes and strategies he discusses in his book is confirmed by the qualms he expresses about Preller's claim that the human intellect is ordered to a reality it cannot know. Williams first warns that this flat formulation damagingly ignores the complexities of what knowledge might mean; then he says that

the process we are seeking to characterize is one in which we are brought to a point where to go on speaking at all requires a shift of expectation, away from the assumption that there will be a point of descriptive closure... When we acknowledge the impulse to continue when 'ordinary' description is done with, we... seek a register for speaking in this situation [that] might indeed be described as a 'yielding to what we know'...looking for a discourse that can be acknowledged between speakers. (EW, 8-9)

But the difficulty encountered with religious talk of 'energy that is not involved in exchanges' or of 'that on which all beings depend' is not generated merely by the mistaken expectation that they're meant descriptively, and so can't be resolved simply by seeing that they're really functioning representationally. The difficulty is that their significance for us in this context lies in our dismantling (and thereby evoking) their descriptive meaning, and refusing to assign any other kind (representational or otherwise). If the significance of such God-talk is precisely that it is constructed by removing just the conditions that confer sense on it in everyday contexts, then its significance is not best described as a way of 
going on speaking non-descriptively; it is a way of not going on speaking (descriptively or otherwise). It is not a mode of discourse, but a mode of 'discourse' - discourse deconstructed. In short, Williams seems to present talk about God as one amongst a heterogeneous range of intelligible modes of linguistic representation that disrupt our routine descriptive concerns, however distinctive it may be; whereas I want to suggest that at least core regions of such talk about God are essentially discontinuous with sense-making, whether descriptive or representative. Otherwise put: if these kinds of talk about God count as modes of representation in Williams' sense, then either that category elides an important distinction (between eccentric or excessive modes of sensemaking and refusals of sense, between riddles and great riddles), or it misapprehends the distinctive way in which talk about God disrupts speech.

Even this second glance at Williams' argument is not, however, enough to conclude that he and I are fundamentally at odds on these matters. To begin with, my own account of the nonsensicality of talk about God lays much stress on the continuities between more everyday modes of language use and the uses to which religious believers resort. First, there are the internal relations between nonsensical religious discourse and its intelligible kindred, the kind found in ordinary, transparent religious language-games and practices of the kind D.Z. Phillips and other concentrate. It is only in the context provided by the latterthe context of a religious form of life - that the sense-rejecting practices upon which I concentrate could have the significance I claim to discern. In addition, I devote two lectures to arguing that analogous religious uses of language (to which the nonsensical ones belong) tap into the basic nature of words as projective (always already open to new contexts of use), and so into the inherent relatedness of meaning in our forms of life with language. Given my focus on Wittgenstein, I use such phenomena as family resemblance and secondary sense 
to exemplify the phenomenon; but many of the phenomena Williams discusses would work equally well for my argument.

Such continuity is in fact inherent in my argument that the relevant kinds of talk about God are constructed by stripping familiar forms of word use of their sense-making conditions. That absence of sense is necessarily the result of violence done to, and so depends for its significance on a continued relation to, everyday ways of making sense. To put it in Williams' terminology, such religious talk is a mode of achieving silence; and as his concluding lecture on that topic stresses, there is no such thing as an unframed or pure silence: 'Silence for us is always the gap that occurs here, in this specific place between words or images' (EW,157). Even if any silence does specifically disrupt and modify an equally concrete mode of speech, however, does it follow - as Williams infers - that it 'thus itself "says" something' (EW, 157)? Well: when I stress that such talk about God is senseless, I don't mean that employing words in this senseless way is itself unintelligible - for we can make sense of those who do it, in part by seeing what they're doing as extending a creative use of language to its unintelligible limit, and so can perhaps regard what they are doing as a kind of linguistic responsiveness to reality, as a humanly acknowledgeable or acknowledgeably human employment of language. But calling it a kind of 'saying' is itself justifiable only if those inverted commas remain firmly in place.

My approach plainly taps into a broader tradition of negative theology, with its extreme sensitivity to the extent to which God's transcendence constitutively resists any attempts to apply language to it. When Williams addresses this manifestation of silence in theology, he first stresses its dangers, citing Eastern theologians' anxiety that it risks becoming 'a conceptual game whose outcome is simply a kind of definitional fastidiousness: as if we were just saying 'not quite' about various predications concerning infinite agency' (EW, 174). But he is willing to endorse versions of such negative theology which wholly 'resign 
the mind... to sheer receptivity' and abandon 'all aspiration to definitive experience of God'; for then 'ultimately, what matters is... a developing understanding of how our thinking and feeling become... dispossessed of controllable material' (EW, 174).

That, however, is exactly the understanding of religious discourse that my version of negative theology points towards: for its silences are achieved precisely by an imaginative response to great riddles whose provenance is the revealed authority of scripture, and so are framed by a conception of the authority of revelation that emphasizes its requirement that we absolutely or unconditionally cede control of our speech and forms of living. This Thomist reading demands exactly the sense of dispossession, of transcending registers of order and manipulation, in our life with words that Williams says a serious negative theology must deliver (and that would be anchored in a broader form of religious life in which dispossession is embodied or enacted). And such an account would certainly allow Williams to make good on his early and vital acknowledgement that language about God, whilst being far from unique in having a disruptive effect, does 'propose the most serious disruption of all, because it proposes... something about all possible subjects of discourse... so what is going to be said about it is going to be linguistically eccentric in a uniquely marked way, and the role of... strategic silence becomes central' (EW, $31)$.

At third glance, then, I see a deep continuity underlying the more apparent discontinuities between my approach and that of Williams, and one that might be framed in the most general terms that Williams provides for his lectures. For he initially presents himself as trying to recover a defensible form of natural theology in the light of currently influential criticisms of its supposed tendency to discount the role of revelation, and so of God's capacity actively to interrupt our natural processes of thought, experience and speech. For Williams, this 
overlooks the extent to which a natural theology that is properly sensitive to the pervasive eccentricities of normal life with language already delineate a space within which that divine disruptive capacity can be manifest and acknowledged. His lectures practice just such a natural theology: they foreground aspects of our encounter with reality which are exactly as we should expect if the world really were what the Christian discourse of revelation claims it to be (cf EW, 180). Then my lectures could be read as an attempt to understand that discourse of revelation as the self-emptying fulfilment of the discursive frames which make possible the understanding of nature, and so natural theology. Both approaches therefore present natural theology and the theology of revelation as each other's other, internally related and so mutually constitutive. They show, in other words, not only that revelation and natural theology are essentially complementary, but that the same might be said of these Gifford lectures and my Stanton Lectures.

\author{
Stephen Mulhall
}

New College, Oxford 